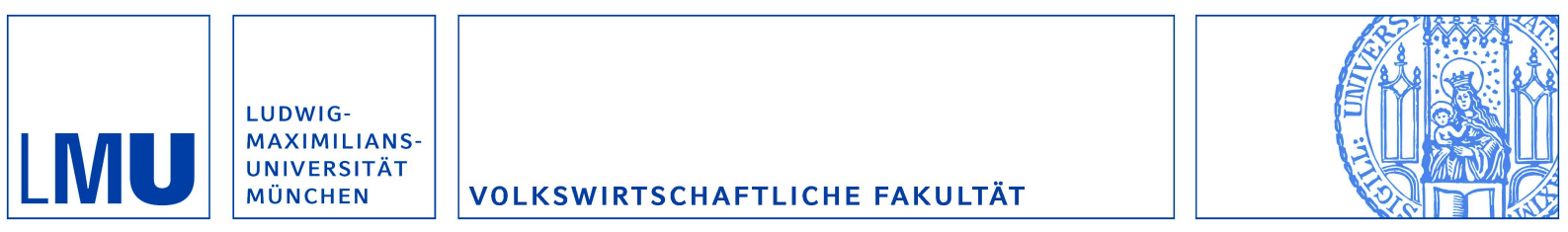

Lehner, Maria und Schnitzer, Monika:

Entry of Foreign Banks and their Impact on Host Countries

Munich Discussion Paper No. 2006-29

Department of Economics

University of Munich

Volkswirtschaftliche Fakultät

Ludwig-Maximilians-Universität München

Online at https://doi.org/10.5282/ubm/epub. 1208 


\title{
Entry of Foreign Banks and their Impact on Host Countries
}

\author{
Maria Lehner* \\ University of Munich
}

\author{
Monika Schnitzer ${ }^{\dagger, \ddagger}$ \\ University of Munich and CEPR
}

September 2006

\begin{abstract}
Foreign bank entry is frequently associated with spillover effects for local banks and increasing competition in the local banking market. We study the impact of these effects on host countries. In particular, we ask how these effects interact and how they depend on the competitive environment of the host banking market. An increasing number of banks is more likely to have positive welfare effects the more competitive the market environment, whereas spillovers are less likely to have positive welfare effects the stronger competition. Hence, competitive effects seem to reinforce each other, while spillovers and competition tend to weaken each other.
\end{abstract}

JEL classification: F37, G21, L13, O16

Keywords: foreign bank entry, multinational bank, competition in banking, spillover effects

\footnotetext{
*University of Munich, Akademiestr. 1/III, 80799 Munich, Germany. Tel: +49 8921802766. Email: maria.lehner@lrz.uni-muenchen.de

${ }^{\dagger}$ Corresponding author. University of Munich, Akademiestr. 1/III, 80799 Munich, Germany and CEPR. Tel: +49 892180 2217. Email: schnitzer@lrz.uni-muenchen.de

${ }_{\ddagger}^{\ddagger}$ Financial support from the German Science Foundation through SFB/TR 15 and DFGSchn422/4-1 is gratefully acknowledged.
} 


\section{Introduction}

One of the most striking developments in the banking sector in transition and emerging market economies has been the sharp increase of foreign bank entry during the last decade. For instance, the market share of foreign banks in Eastern Europe has gone up from on average around $11 \%$ in 1995 to around $65 \%$ in 2003 (Claeys and Hainz, 2006). The situation looks similar in Latin America, and foreign bank entry is likewise on the rise in other emerging economies in Asia, Africa and the Middle East, albeit at a lower pace (Clarke et al, 2003).

Why do transition and emerging economies open up their banking markets and what are the consequences? Governments liberalize their banking markets in order to attract new capital and to promote the restructuring of their often rather inefficient banking systems. One possible channel for how foreign banks may foster such a restructuring process is spillover effects from foreign to domestic banks, another possible channel could be the increase in competition. However, the opening up of banking markets can also entail large risks since domestic banks need to undertake huge investments to become competitive to foreign banks.

The aim of our paper is to analyze the impact of foreign bank entry on host countries, emphasizing the transition and emerging market context. We study in particular the two channels through which foreign banks may have an influence on the domestic banking market, spillovers and an increase in competition. We analyze how they affect the domestic banks' incentives to improve on their efficiency and host countries' social welfare. We ask in particular how the two channels interact, i.e. whether or not they reinforce each other. We also investigate how different modes of foreign bank entry differ in their impact on the domestic banking market.

For this purpose, we set up a model of spatial bank competition à la Salop. Banks compete in prices for potential borrowers that engage in investment projects of uncertain return. Banks in our model differ with respect to screening abilities. Foreign banks have perfect screening ability while, for simplicity, domestic banks in the closed economy are assumed not to have access to a screening technology. 
When the domestic banking market opens up, foreign banks are given the possibility to enter the market, either via the acquisition of a domestic bank or through a greenfield investment. Due to spillover effects from foreign to domestic banks, domestic banks gain access to a screening technology, albeit not as sophisticated as that of foreign banks. Domestic banks then have the choice to undertake an investment in order to obtain the perfect screening technology.

Our first focus is on the implications of spillover effects on the efficiency of liberalizing banking markets. We find that with rising spillovers the incentives of domestic banks to invest in the perfect screening technology fall because the higher the spillover effects, the less a bank gains by investing in screening. Thus, we identify a trade-off between two regimes. High spillover effects result in a market in which just a few banks dispose of perfect screening ability while a large number of domestic banks know to screen fairly well. In contrast, low spillovers imply a situation in which a lot of domestic banks invest in the perfect screening technology but some domestic banks screen only very imperfectly.

A second major issue we study is the role of competition in terms of the number of banks operating in the market. Since the number of banks in the economy increases in case of de novo investments but stays constant with acquisition entry, greenfield entry corresponds to a higher competitiveness in the market. Hence, analyzing the effect of competition allows us to draw some conclusions concerning the different implications of acquisition and de novo entry for liberalizing banking markets.

We find that a larger number of banks operating in the market leads to declining repayment rates as well as to smaller market shares and, thus, tends to decrease the incentives of domestic banks to invest in screening. We conclude that investment incentives for domestic banks are higher in case of acquisition than in case of greenfield entry.

A major focus of our analysis constitutes the interaction of spillovers and competition. We find that spillovers and competition reinforce each other in their negative impact on the number of domestic banks investing in screening. Thus, 
the different implications of acquisition and greenfield entry widen when spillovers rise.

We study further how the impact of spillovers and competition in the number of banks depends on the competitiveness of a market in terms of the degree of product differentiation. Our analysis shows that with lower product differentiation and thus higher competitiveness, the negative impact of spillovers and competition on the investment incentives of domestic banks is dampened. Hence, the more competitive a market, the less the entry mode matters for the incentives of domestic banks to invest in screening.

From a social welfare point of view, the impact of spillovers and competition in the number of banks and, thus, the entry mode on welfare is ambiguous and depends on the degree of product differentiation. When product differentiation is high, welfare increases with spillovers and decreases with the number of banks operating in the market. In contrast, with low product differentiation lower spillovers as well as higher competition and, thus, greenfield entry, is to be preferred.

Our major conclusions from the welfare analysis are thus as follows: both modes of competition, a larger number of banks and lower product differentiation, work as a form of complements. In particular, a larger number of banks operating in the market and thus greenfield entry can, in general, only be welfare enhancing when competitive pressure in terms of lower product differentiation is also sufficiently large. Hence, one channel of competition is not sufficient in order to raise welfare, rather, a high level of both competition effects is necessary for enhancing welfare. In contrast, we find that spillovers constitute a form of substitute relative to either channel of competition, i.e. potential positive welfare effects of spillovers are lower the stronger is competition.

Foreign bank entry has received surprisingly little attention in the literature so far. Goldberg (2004) raises the issue by comparing foreign direct investments in the financial and the manufacturing sector, focusing on the implications for emerging market economies. Attempts to analyze foreign bank entry in a theoretical framework have been scarce. Dell'Ariccia, Friedman and Marquez (1999) 
point to the problem potential entrant banks may face in distinguishing good from bad borrowers that have already been rejected by incumbent banks. In line with this approach, Dell'Ariccia and Marquez (2004) analyze the trade-off between superior information of host country banks and lower refinancing costs of foreign banks entering the market. Buch (2003) sets up a theoretical model of foreign bank entry and finds empirical support for the hypothesis that large information barriers discourage entry of foreign banks. Hauswald and Marquez (2003) consider the possibility of information spillovers from incumbent host country banks to potential entrants and show that, as a result, interest rates and bank profits decrease. Kaas (2004) presents a model of spatial loan competition and arrives at the conclusion that foreign bank entry is generally too low compared to the social optimum. Claeys and Hainz (2006) as well as Van Tassel and Vishwasrao (2005) look at how different entry modes of foreign banks affect competition in a liberalized banking market. Both approaches imply that greenfield entry leads to more competition and thus lower interest rates in the host banking market.

We contribute to this strand of literature by introducing spillover effects into a model of spatial bank competition. In this respect, our paper corresponds to theoretical approaches analyzing the effect of spillovers on R\&D investment and cost reduction. Negative effects of spillovers on R\&D incentives and cost reduction effort are stated by Spence (1984). In contrast, Cohen and Levinthal (1989) as well as Levin and Reiss (1988) both find theoretical and empirical support for the hypothesis that intra-industry spillovers may lead to an increase in R\&D investment.

Görg and Strobl (2001) find that empirical evidence on spillovers is mixed and point to the role of the underlying econometric framework. Coe and Helpman (1995) and Coe, Helpman and Hoffmaister (1997) suggest that foreign R\&D via international trade entails spillovers in the sense that total factor productivity rises both in developed and in developing countries. Similarly, Beck, Levine and Loayza (2000) conclude that financial intermediary development raises total factor productivity growth. Blomström and Kokko (1998) also support this view. In their survey of literature on spillovers from multinational corporations to host country firms they find evidence that the effect of spillovers is positive and increases with 
the degree of competition in the host country. Ceccagnoli (2005) indicates that spillovers increase R\&D effort when the number of innovating firms is small.

In addition to the impact of spillovers, we study the effect of competition on the incentives of host country banks to invest in better screening skills. Our model relates to a strand of theoretical literature on the influence of competition on innovation incentives. Vives (2004) shows that an increasing number of firms in the market implies lower R\&D investment while rising competition in terms of increasing product substitutability encourages R\&D incentives. Raith (2003) investigates the effect of mounting competition on cost reducing effort in a principal agent setting and concludes that both an increasing number of firms in the market and rising product substitutability increase the incentives to invest in cost reduction. In contrast, Boot and Marinč (2006) find that fiercer competition in terms of an increasing number of banks operating in the market reduces banks' efforts to invest in better monitoring technologies. Schnitzer (1999) studies the impact of competition on the efficiency of credit allocation. She finds that screening incentives rise with the number of informed banks and that increasing competition raises the likelihood of bad loans. Hauswald and Marquez (2005) present a model of spatial bank competition in which banks can invest in strategic information acquisition about the quality of borrowers' investment projects and find that rising competition decreases investment in screening. Similarly, Broecker (1990) and Sharpe (1990) show that increasing competition decreases the quality of a banks loan portfolio.

Empirical papers investigating increasing competition in the light of foreign bank entry are numerous. Claessens, Demirgüç-Kunt and Huizinga (2001) suggest that higher competitive pressure due to foreign bank entry implies an increase in the efficiency of host country banks and thus higher welfare in economies liberalizing their banking markets. Fries and Taci (2005) study the cost efficiency of banks in Eastern European Countries and find that costs of all banks are lower when the presence of foreign banks in a country is high. Martinez Peria and Mody (2004) distinguish between acquisition and greenfield entry in the context of Latin America. They find that the interest rate spread of foreign banks entering via a de novo investment is lower than that of banks entering via the acquisition of a host 
country bank. Moreover, their analysis suggests that a higher presence of foreign banks leads to lower costs of all banks operating in the market.

The remainder of the paper is organized as follows. The next section describes the set-up of the model. In section 3 we study the equilibrium in the banking market. Section 4 analyzes the comparative statics of spillover effects and competitive pressure on the efficiency of the domestic banking market. We present the welfare analysis in section 5. Section 6 concludes.

\section{The Model}

Consider a continuum of borrowers with mass $m$ being uniformly distributed along a circular road with circumference 1 . Each borrower can engage in one investment project that requires an initial outlay of $i, i>0$. Borrowers have either good or bad projects. It is common knowledge that the fraction of borrowers with good projects is $\gamma$ and the fraction of borrowers with bad projects is $1-\gamma, 0<\gamma<1$. In case the project is good it generates a return $v>0$ with certainty while a bad project always fails yielding a return of zero. The returns of the projects are observable and contractible. We assume that ex ante borrowers do not know the quality of their projects. Hence, we think of borrowers as not being capable to evaluate correctly the outcome of their investment projects because of lacking expertise in project evaluation. ${ }^{1}$ Borrowers are not endowed with any initial wealth and therefore need to apply for credit at the banks, the only source of finance in our model.

The banking sector consists of $n$ banks that are located equidistantly along the circular road. ${ }^{2}$ The location of a bank signifies its specialization in a certain credit product or industry. Banks compete in the repayments $r_{j}, j=1, \ldots, n$ they simultaneously ask from the borrowers. Borrowers whose investment projects yield a return of $v$ must repay $r_{j}$ to the bank whereas borrowers whose projects fail do

\footnotetext{
${ }^{1}$ Similar assumptions can be found e.g. in Hauswald and Marquez (2005) or Kaas (2004).

${ }^{2}$ For our analysis to be interesting we assume that the number of banks $n$ in the market is not too small.
} 
not repay their loan. We assume that banks in the closed domestic banking market do not have access to a screening technology so that all borrowers are offered a credit of size $i$ because by assumption, $\gamma r_{j}>i .^{3}$ We take it as given that each bank disposes of enough funds to finance all borrowers applying for a credit. Borrowers base their decision at which bank to apply for credit on the repayments $r_{j}$ asked by the banks and the transport costs they have to incur to travel to the bank. The transport costs express the preferences borrowers have for a particular type of bank. We assume that transport costs $t x$ are proportional to the distance $x$ between the borrower and the bank. Furthermore, we assume that the return of a good project $v$ is high enough so that the market is covered at equilibrium prices. Borrowers and banks are risk neutral and maximize profits. The time structure of the model is as follows.

At stage 1, the domestic banking market is opened up to a number $l$ of foreign banks. ${ }^{4}$ We distinguish between two entry modes. Foreign banks can enter either via a greenfield investment or via the acquisition of a domestic bank. When banks enter via a de novo investment a foreign subsidiary is established in the domestic banking market and so the number of banks operating in the market increases. In contrast, entry via acquisition leaves the number of banks constant since we consider an acquired domestic bank as a foreign bank. As a matter of simplicity, we assume that there are no costs of entry. Banks locate equidistantly along the circular road. We assume that foreign banks dispose of perfect screening ability. Consequently, foreign banks finance all borrowers with good projects that ask for a credit whereas a borrower with a bad project is never offered a credit. ${ }^{5}$ Without loss of generality, we assume that screening a borrower is costless for a foreign bank.

\footnotetext{
${ }^{3}$ Think for instance of the transition countries where due to the planning of the economy no screening took place during the communist era.

${ }^{4}$ For our analysis to be interesting we assume that there is a sufficiently large number of domestic banks that can be affected by foreign bank entry, i.e. $\frac{l}{n}$ is not close to 1 .

${ }^{5}$ In our analysis we concentrate on the advantage of foreign over domestic banks regarding the processing of hard information. Domestic banks could at least in segments of old borrowers dispose of superior soft information. However, we abstract from this aspect since we focus on the early liberalization period in transition countries with young firms predominating. The higher importance of hard compared to soft information processing technologies for screening abilities is confirmed e.g. by Panetta, Schivardi and Shum (2005).
} 
We assume that with foreign banks entering the domestic banking market spillover effects occur. For instance, spillovers could realize via an improvement in the human capital stock when domestic staff is employed and trained by foreign banks. With some fluctuations of workers, better risk management techniques, superior forms of organization, better data processing technologies etc. can then be implemented in domestic banks alike. Spillovers could also realize via the replication of high quality financial services offered by foreign banks. Furthermore, foreign banks are likely to press for an improved regulatory supervision of the banking markets they enter. Spillover effects are modeled as follows. We assume that with the entry of foreign banks domestic banks obtain access to an imperfect screening technology. Domestic banks can therefore identify the fraction $1-\alpha$, $0<\alpha<1$, of borrowers investing in bad projects but cannot distinguish between the remaining fraction $\alpha$ of borrowers with bad projects and the borrowers with good projects. Accordingly, domestic banks finance the fraction $\alpha$ of borrowers investing in bad projects as well as all borrowers with good projects applying for credit. However, the fraction $1-\alpha$ of borrowers with bad projects is denied credit. Hence, the higher is the spillover effect, the better is the quality of the screening technology the domestic banks obtain and the lower is the fraction $\alpha$ of borrowers with bad projects financed in the banking market opened to foreign banks. Without loss of generality, we assume that there are no per borrower screening costs for all banks.

At stage 2, domestic banks have the possibility to invest a fixed cost $F>$ 0 in order to obtain the perfect screening technology. ${ }^{6}$ This decision is taken simultaneously by all domestic banks. Hence, domestic banks need to weigh the size of the fixed cost against the costs associated with the financing of borrowers with bad projects in case they do not invest in the perfect screening technology. As a result, the situation in the open domestic banking market looks as follows. Three types of banks can operate in this market: foreign banks, domestic banks that dispose of the perfect screening technology, and domestic banks that only screen imperfectly.

\footnotetext{
${ }^{6}$ Our qualitative results would remain unaffected if we introduced the size of the fixed cost to vary with the degree of spillovers.
} 
At stage 3, borrowers apply for credit at the banks. Banks engage in screening the borrowers. Banks that have access to the perfect screening technology make credit offers only to borrowers with good projects whereas banks not having invested in screening offer a credit to borrowers investing in good projects and the fraction $\alpha$ of borrowers with bad projects. Borrowers with bad projects that are denied credit do not apply for credit at another bank. This is due to the fact that with the screening procedure the borrowers learn about the bad quality of their investment opportunities and so give up on realizing their projects. ${ }^{7}$

At stage 4, returns realize and all borrowers investing in good projects pay back their loan. We solve the game by backward induction.

\section{Equilibrium in the Banking Market}

In this section, we study the equilibrium of the domestic banking market with foreign bank entry. We first calculate the equilibrium repayments different types of banks ask from the borrowers for a given number $k$ of domestic banks that invest in perfect screening. Then, we derive the equilibrium number of domestic banks $k^{*}$ that invest in the perfect screening technology. We assume that all banks are randomly allocated along the circle, so each location is equally likely for each bank. Thus, we can define the probability that the neighboring bank of a perfectly screening bank also has access to the perfect screening technology as $q:=\frac{l+k-1}{n-1}{ }^{8}$

\footnotetext{
${ }^{7}$ In our model, borrowers do not realize any utility from investing in a bad project. Alternatively, we could allow a certain fraction of the borrowers to realize some private benefit from investing in a bad project. In that case, some of the rejected borrowers would reapply at other banks and eventually obtain financing. This would weaken but not substantially change our results.

${ }^{8}$ Note that banks can only build expectations about whether their neighbours invest in screening or not and, accordingly, charge high or low repayments. This assumption is used as a modelling device in order to avoid asymmetric equilibria and keep the model tractable. We refer to Aghion and Schankerman (2004) for further justifications of this assumption.
} 
Proposition 1 In equilibrium, banks with perfect screening technology charge a repayment $r_{L}$, whereas banks with imperfect screening technology charge a repayment $r_{H}>r_{L}$, where

$$
\begin{aligned}
& r_{L}=i+\frac{t}{n}+\frac{\alpha i(1-\gamma)}{\gamma} \frac{1-q}{2} \\
& r_{H}=i+\frac{t}{n}+\frac{\alpha i(1-\gamma)}{\gamma}\left(1-\frac{q}{2}\right)
\end{aligned}
$$

Proof: see Appendix.

The equilibrium prices described in Proposition 1 result in the following equilibrium profits of foreign banks, $\pi_{F B}$, of domestic banks that invest in the perfect screening technology, $\pi_{D B, L}$, and of domestic banks that do not invest in screening, $\pi_{D B, H}:$

$$
\begin{aligned}
& \pi_{F B}=\frac{\gamma m}{t}\left[\frac{1}{2}(1-q) \frac{\alpha i(1-\gamma)}{\gamma}+\frac{t}{n}\right]^{2} \\
& \pi_{D B, L}=\frac{\gamma m}{t}\left[\frac{1}{2}(1-q) \frac{\alpha i(1-\gamma)}{\gamma}+\frac{t}{n}\right]^{2}-F \\
& \pi_{D B, H}=\frac{\gamma m}{t}\left[-\frac{q}{2} \frac{\alpha i(1-\gamma)}{\gamma}+\frac{t}{n}\right]^{2} .
\end{aligned}
$$

Note that the profits of all banks depend negatively on the share of perfectly screening banks in the market. The intuition behind this is that first, the more banks operate in the market that screen perfectly the lower will be the expected market share for any individual bank in the market because the likelihood that it needs to share its market with a perfectly screening bank increases. Second, a higher fraction of perfectly screening banks in the market leads to lower repayments both types of banks can ask from the borrowers in equilibrium; this, in turn, decreases profits for all banks. However, the profits of banks that have access to the perfect screening technology fall by more than those of imperfectly screening banks. On the one hand, this is due to the fact that the reduction in the size of the repayment is weighed by a larger expected market share these banks cover compared to the banks screening imperfectly. On the other hand, the more banks 
operate in the market that screen perfectly the lower are the costs arising from borrowers with bad projects if a bank does not invest in the screening technology. This is due to the fall of the expected market share and hence the smaller number of borrowers with bad projects asking for a loan.

Next, we derive the equilibrium number $k^{*}$ of domestic banks that invest in the perfect screening technology. When deciding about whether to invest in screening or not, a domestic bank weighs the required fixed cost against the costs associated with the financing of borrowers with bad projects if it does not invest in screening. Proposition 2 characterizes the three different kinds of equilibria we get for low, medium and high fixed costs for the perfect screening technology.

Proposition 2 There exist values of fixed costs $\underline{F}$ and $\bar{F}$, with $\underline{F}<\bar{F}$, such that (1) for low values of the fixed cost $F \leq \underline{F}$, all domestic banks invest in the perfect screening technology;

(2) for high values of the fixed cost $F \geq \bar{F}$, no domestic bank invests in the perfect screening technology;

(3) for intermediate values of the fixed cost in the range $\underline{F}<F<\bar{F}$ a number $k^{*}, 1 \leq k^{*} \leq n-l$, of domestic banks invests in the perfect screening technology. The number $k^{*}$ is the integer number that lies between

$$
\underline{k}=\frac{n}{2}-l-\frac{2 t \gamma(n-1)}{\alpha i(1-\gamma)}\left[\frac{F}{m \alpha i(1-\gamma)} \frac{(n-1)}{(n-2)}-\frac{1}{n}\right]
$$

and

$$
\bar{k}=\underline{k}+1 .
$$

Proof: see Appendix.

The decision of a domestic bank to invest in screening or not clearly depends on what all other domestic banks do. The higher the number of domestic banks that invest in screening the less attractive it becomes for a bank to spend the fixed cost. This is due to the fact that with a rising fraction of perfectly screening banks in the market the profit of a bank that has access to the perfect screening 
technology decreases by more than the profit of a bank screening imperfectly as explained above. If the fixed cost is very low, however, the investment incentives are so large that it pays for a domestic bank to invest in the screening technology even if all other domestic banks also invest in screening. Instead, if the fixed cost is very large then it does not pay for a domestic bank to spend the fixed cost even if all other domestic banks do not invest in the screening technology, neither. For intermediate ranges of the fixed cost these two extreme equilibrium outcomes are not feasible.

We can show that for intermediate values of the fixed cost an equilibrium exists in which exactly $k^{*}$ domestic banks invest in the screening technology whereas the remainder of domestic banks does not invest in screening. Such an equilibrium is stable if $\pi_{D B, L}\left(k=k^{*}\right) \geq \pi_{D B, H}\left(k=k^{*}-1\right)$ and $\pi_{D B, H}\left(k=k^{*}\right) \geq$ $\pi_{D B, L}\left(k=k^{*}+1\right)$. The value $k^{*}$ that satisfies these two conditions is described in Proposition 2. Note that in equilibrium, banks are not indifferent between investing and not investing in screening since the profit of banks that screen perfectly lies slightly above the profit of banks screening imperfectly. Given $k^{*}$, however, no domestic bank has an incentive to deviate because that would imply even lower profits.

\section{Impact of Spillovers and Competition on the Efficiency of the Domestic Banking Market}

In this section we study how spillovers as well as competition affect the equilibrium number of domestic banks investing in screening, $k^{*}$. In particular, we concentrate on the interaction of spillovers and competition in terms of the number of banks operating in the market. Moreover, we analyze how the strength of these effects depends on the competitiveness prevailing in the market as measured by the degree of product differentiation, $\frac{1}{t}$. We focus first on the case of intermediate fixed costs of screening in which $k^{*}$ domestic banks invest in the perfect screening technology. Then, we characterize how the parameter range of fixed costs for which $k^{*}$ constitutes an equilibrium changes with spillover and competition effects. 
The following Proposition characterizes how $k^{*}$ is influenced by spillover effects. We use $(-\alpha)$ to capture the size of the spillovers. The larger $(-\alpha)$, i.e. the smaller $\alpha$, the larger are the spillover effects.

Proposition 3 The equilibrium number of domestic banks that invest in perfect screening is a decreasing and concave function of the size of the spillover effect. That is,

$$
\frac{d k^{*}}{d(-\alpha)}<0 \text { and } \frac{d^{2} k^{*}}{d(-\alpha)^{2}}<0
$$

Proof: see Appendix.

The intuition behind this result is as follows: with rising spillover effects even those domestic banks that do not invest in perfect screening are able to identify a larger fraction of borrowers with bad projects. This, in turn, allows the banks to become more competitive in the sense that they can decrease the repayment they ask from the borrowers because the negative effect of an increasing market share, i.e. losses from bad projects, is reduced.

Consequently, banks investing in the perfect screening technology also need to lower their repayment offers and, in addition, their expected market share will fall. Thus, domestic banks that do not invest in the perfect screening technology obtain larger profits whereas profits of banks with perfect screening ability decrease. Hence, the incentives to invest in the perfect screening technology and, accordingly, the number of domestic banks investing in screening falls when spillovers rise.

Note, however, that spillover effects have a positive influence on the overall efficiency of the domestic banking market in the sense that the domestic banks that did not screen at all in the closed banking market obtain access to an imperfect screening technology. Consequently, we identify a clear trade-off: with low spillover effects a large number of perfectly screening domestic banks operates in the market but there are also a few banks that screen very imperfectly. The situation is 
different with high spillovers: the number of domestic banks screening perfectly is rather low but all other domestic banks not investing in screening operate quite efficiently due to the large spillovers.

Furthermore, as stated in the following Lemma, we find that with rising spillovers the range of fixed costs $F$ for which an equilibrium with all domestic banks investing in screening is feasible shrinks and the range of $F$ for which no domestic bank invests in screening enlarges. Hence, increasing spillovers decrease the number of domestic banks investing in the screening technology as well as the chances that an equilibrium establishes in which all domestic banks invest in screening.

Lemma 1 With increasing spillover effects the threshold values $\underline{F}$ and $\bar{F}$ determining the three possible equilibrium outcomes decline, that is

$$
\frac{d \underline{F}}{d(-\alpha)}<0 \quad \text { and } \quad \frac{d \bar{F}}{d(-\alpha)}<0 .
$$

Proof: see Appendix.

Next, we analyze the impact of competition in terms of the number of banks operating in the market $n$ on the equilibrium number of domestic banks that invest in screening. ${ }^{9}$ Thereby, we capture the impact of the different entry modes on the investment incentives of domestic banks. Note that when banks enter via a de novo investment a foreign subsidiary is established in the domestic banking market and so the number of banks operating in the market increases. ${ }^{10}$ In contrast, entry via acquisition leaves the number of banks operating in the economy constant since only the ownership of a domestic bank that is acquired by a foreign bank changes. Proposition 4 characterizes how competition as measured by the number of banks affects $k^{*}$.

\footnotetext{
${ }^{9}$ We treat the number of banks in the market as exogenous. Note that entry during the early liberalization period in transition countries was in general heavily regulated. Hence, we think of the number of banks in the market as a policy makers' decision variable and will derive the welfare maximizing policy regarding $n$ later on.

${ }^{10}$ Thereby, we account for the major difference between greenfield and acquisition entry, namely the higher competitiveness prevailing in a market when entry occurs via de novo investment.
} 
Proposition 4 The number of domestic banks that invest in perfect screening is a decreasing and concave function of the overall number of banks in the market. That is,

$$
\frac{d k^{*}}{d n}<0 \quad \text { and } \quad \frac{d^{2} k^{*}}{d n^{2}}<0
$$

Proof: see Appendix.

The intuition here is as follows: an increasing number of banks leads to lower equilibrium repayment rates as well as to lower market shares for all banks. However, domestic banks not investing in screening lose relatively less since a falling market share also means a smaller number of bad borrowers financed.

Proposition 4 further implies that entry via a greenfield investment will decrease the equilibrium number of domestic banks investing in screening by more than entry via acquisition.

In addition, we find that mounting competition and, accordingly, greenfield entry not only decreases the incentives of domestic banks to invest in screening but also the chances that an equilibrium emerges in which all domestic banks invest. Instead, the parameter range for which no domestic bank invests in the screening technology widens. These findings are summarized in Lemma 2.

Lemma 2 An increasing number of banks operating in the market leads to a fall both in $\underline{F}$ and $\bar{F}$, that is

$$
\frac{d \underline{F}}{d n}<0 \quad \text { and } \quad \frac{d \bar{F}}{d n}<0 .
$$

Proof: see Appendix.

Furthermore, our findings indicate that de novo entry results in lower shares of perfectly screening banks in the market than acquisition entry as is stated in Lemma 3. 
Lemma 3 The entry of a marginal foreign bank via the acquisition of a domestic bank keeps the share of perfectly screening banks in the market constant. In contrast, the entry of a marginal foreign bank via a de novo investment reduces the share of perfectly screening banks in the market.

Proof: see Appendix.

Hence, when we refer to the efficiency of a banking market as the share of all banks in the market that screen perfectly, we find that acquisition entry entails higher efficiency than greenfield entry.

We now turn to the interaction of spillovers and competition in the number of banks operating in the market. Our results are summarized in Proposition 5.

Proposition 5 Spillovers and competition in the number of banks operating in the market reinforce each other in their negative impact on the number of domestic banks investing in screening, $k^{*}$. That is,

$$
\frac{\partial^{2} k^{*}}{\partial(-\alpha) \partial n}<0 .
$$

Proof: see Appendix.

We find that the larger the spillovers the higher is the absolute marginal negative impact of an increasing number of banks operating in the market on the incentives of domestic banks to invest in screening and vice versa. Hence, spillovers and competition reinforce each other in their negative impact on the number of perfectly screening domestic banks. We conclude that spillovers and competition work as complements with respect to the investment incentives of domestic banks.

The intuition for this result is as follows. Higher spillovers entail larger market shares of domestic banks not investing in screening. Thus, higher spillovers imply that an increase in the number of banks operating in the market results in a loss of relatively more borrowers with bad projects. Hence, the negative impact of 
an increasing number of banks on the investment incentives of domestic banks is reinforced with larger spillovers.

It is interesting to see that contrary to the often claimed positive role of spillovers and competition for financial development we arrive at the opposite result. ${ }^{11}$ Even more, in our model one effect cannot substitute for the other one, rather, both effects reinforce each other in their negative impact on the incentives of domestic banks to invest in screening.

Note also that the higher the spillovers, the more distinct the implications of de novo and acquisition entry. This is due to the fact that with larger spillovers the negative impact of de novo investments on the equilibrium number of domestic banks investing in screening becomes stronger.

For our policy conclusions it is important to know how the strength of the spillover and competition effects just described depends on the competitive environment in the domestic banking market. In our model we capture this by the degree of product differentiation $\frac{1}{t}$. Before we address this issue in more detail, we first give an intuition of how competitive pressure $\frac{1}{t}$ affects the incentives of domestic banks to invest in screening. Our results are summarized in Proposition 6.

Proposition 6 In case of $l<\frac{n-2}{2}$, there exists a fixed cost $F_{1}$, such that the number of domestic banks that invest in perfect screening is a decreasing and convex function of competitive pressure $\frac{1}{t}$ for low values of the fixed cost $F$, i.e. $F<F_{1}$, and an increasing and concave function of competitive pressure $\frac{1}{t}$ for high values of $F$, i.e. $F>F_{1}$. In case of $l>\frac{n-2}{2}$, the number of domestic banks that invest in perfect screening is a decreasing and convex function of competitive pressure $\frac{1}{t}$ independent of the size of the fixed cost F. That is,

\footnotetext{
${ }^{11}$ In our model, higher spillovers and more competition through bank entry make domestic banks invest less in the perfect screening technology. We abstract from potential exit of domestic banks. Since we model the early liberalization period of a banking market and focus on transition countries, we justify this approach by assuming an implicit bailout guarantee for the predominating state domestic banks in the early years of transition.
} 
(1) if $l<\frac{n-2}{2}$ :

$$
\begin{aligned}
\text { for } F<F_{1}, & \frac{d k^{*}}{d\left(\frac{1}{t}\right)}<0 \text { and } \frac{d^{2} k^{*}}{d\left(\frac{1}{t}\right)^{2}}>0 \\
\text { for } F>F_{1}, & \frac{d k^{*}}{d\left(\frac{1}{t}\right)}>0 \text { and } \frac{d^{2} k^{*}}{d\left(\frac{1}{t}\right)^{2}}<0 ; \\
\text { (2) if } l>\frac{n-2}{2}: & \frac{d k^{*}}{d\left(\frac{1}{t}\right)}<0 \text { and } \frac{d^{2} k^{*}}{d\left(\frac{1}{t}\right)^{2}}>0 .
\end{aligned}
$$

Proof: see Appendix.

Here, we identify two countervailing effects, a price effect and a market share effect. On the one hand, with higher competitive pressure all banks need to lower the repayments they charge the borrowers. As a consequence, profits of all banks fall. However, the profit of banks that invest in screening decrease by more than that of banks not investing in screening since the former cover a larger expected market share. Thus, this negative price effect works against investment incentives of domestic banks. On the other hand, increasing competitive pressure implies higher market shares of perfectly screening and lower market shares of imperfectly screening banks. The resulting higher asymmetry of banks with respect to their market shares leads to an increase in the profits of banks investing in screening and a decrease in the profits of banks not investing. Hence, the driving factor implying higher screening incentives when competitive pressure rises is the higher asymmetry of banks in market shares.

The overall outcome depends on whether the market share effect outweighs the price effect or vice versa. The rising asymmetry in market shares is the dominating effect when the number of perfectly screening banks in the market is rather small. For this to be true it must hold that the share of foreign banks in the market is not too large, i.e. $l<\frac{n-2}{2}$, and that the fixed cost for the screening technology takes on rather high values, i.e. $F>F_{1}$, ensuring rather low incentives to invest in better screening. Then, with increasing competitive pressure the difference in the market shares of investing and not investing banks widens and, thus, a bank can gain a lot when investing in the screening technology. For $F<F_{1}$, instead, the negative price effect dominates the positive market share effect. In this case, 
a rise in competitive pressure has a negative impact on the number of domestic banks investing in screening. Note that when foreign banks dominate roughly more than one half of the banking market, i.e. $l>\frac{n-2}{2}$, the negative price effect always outweighs the positive market share effect, independent of the size of the fixed cost $F$. In that case, increasing competitive pressure always has a negative impact on investment incentives.

It is interesting to observe that a rising number of banks operating in the market and higher competitive pressure $\frac{1}{t}$ can have the opposite effect on the incentives of domestic banks to invest in screening. This is due to the fact that both channels of competition in our model work in quite different ways. In the first case, the decisive effect leading to a fall in screening incentives is the smaller fraction of bad borrowers financed by imperfectly screening banks while in the second case, the higher investment incentives are driven by a larger asymmetry of banks in market shares.

We now turn to the impact of the competitiveness of a market $\frac{1}{t}$ on the strength of the spillover and competition effects. Our findings are summarized in Proposition 7 .

Proposition 7 Increasing competitive pressure $\frac{1}{t}$ decreases the absolute marginal negative influence of spillovers and competition in the number of banks on the incentives of domestic banks to invest in perfect screening. That is,

$$
\begin{aligned}
& \frac{\partial^{2} k^{*}}{\partial(-\alpha) \partial\left(\frac{1}{t}\right)}>0 . \\
& \frac{\partial^{2} k^{*}}{\partial n \partial\left(\frac{1}{t}\right)}>0 .
\end{aligned}
$$

Proof: see Appendix.

Hence, increasing competitive pressure $\frac{1}{t}$ mitigates the negative impact of spillovers and competition in the number of banks on the incentives of domestic banks to invest in screening. Accordingly, the lower the differentiation of financial 
products in a market, the less pronounced is the effect of the different entry modes on the investment incentives of domestic banks.

The intuition for this result is as follows. Higher competitive pressure $\frac{1}{t}$ corresponds to smaller market shares of imperfectly screening domestic banks. Thus, larger competitive pressure $\frac{1}{t}$ implies that an increase in spillovers or the number of banks in the market results in a smaller loss of borrowers with bad projects. Hence, the negative impact of rising spillovers and competition in the number of banks on the incentives to invest in screening is dampened with rising competitive pressure.

We conclude that both channels of competition work as substitutes with respect to the incentives to invest in screening. However, the interaction of spillovers and competition is ambiguous. Spillovers and competition in terms of the degree of product differentiation constitute substitutes whereas spillovers and the number of banks in the market behave as complements regarding the investment incentives of domestic banks.

\section{Impact of Spillovers and Competition on Wel- fare}

In this section, we analyze the effects of spillovers and competition on welfare, $W$. Welfare consists of the sum of borrower rents and bank rents. Borrower rents are captured by the willingness to pay of borrowers minus the repayments of borrowers to banks and their transport costs. Bank rents include the revenues of banks minus their costs. We could consider two possible welfare functions. The first possibility is to include the profits of foreign banks in the welfare function. This approach could be justified by assuming that in case of acquisition entry, the price paid to acquire a domestic bank equals all future expected profits of the foreign bank merged with the domestic bank. In case of greenfield entry, a foreign bank may be forced to buy a license equal to all future expected profits of the bank in order to be allowed to enter the market. Alternatively, we could exclude the profits of 
foreign banks from welfare in the domestic economy. However, since the results of both set-ups turn out to be fairly similar we will restrict our presentation to the first approach. ${ }^{12}$

In what follows, we study the impact of spillovers as well as the number of banks in the market and, thus, the entry mode on welfare. Our analysis will show that the influence of both effects on welfare is ambiguous and depends on the degree of product differentiation prevailing in a market. Therefore, we will first give an intuition for the implications of the degree of product differentiation on welfare. Our findings are summarized in Proposition 8.

Proposition 8 Declining differentiation in financial products unambiguously increases welfare. That is,

$$
\frac{\partial W}{\partial\left(\frac{1}{t}\right)}>0
$$

Proof: see Appendix.

As can be inferred from Proposition 8, falling differentiation in financial products and thus rising competitiveness unambiguously increases welfare. This is mainly due to the fact that borrowers have less pronounced preferences for a certain type of bank and, accordingly, lower transportation costs. In addition, mounting competitive pressure leads to larger market shares of perfectly and to smaller market shares of imperfectly screening banks entailing less financing of bad borrowers.

Note that according to our previous analysis the strength of the spillover and competition effects decreases with falling product differentiation. Hence, surprisingly, welfare is maximized when the marginal impact of spillovers and competition in the number of banks is small. We conclude that in a highly competitive market

\footnotetext{
${ }^{12}$ In order to analytically solve for the welfare implications, we focus on the following parameter ranges throughout section 5 . We assume that the share of borrowers with good projects is larger than one half and not arbitrarily close to its boundary values, and that spillovers are not too large i.e. $1-\alpha<0.75$.
} 
with low product differentiation, the often mentioned importance of spillovers and competition for financial development may be overestimated.

We will now study the influence of the size of spillovers and competition in terms of the number of banks on welfare. Both effects depend on the degree of competitiveness $\frac{1}{t}$ prevailing in the market as well as the size of the fixed cost $F$. Our results are summarized in Proposition 9.

Proposition 9 There exists a threshold $F_{2}$ for fixed costs and three thresholds $T_{1}$, $T_{2}$ and $T_{3}, T_{1}<T_{2}<T_{3}$, for the level of competitive pressure $\frac{1}{t}$ with the following properties:

(1) suppose $F<F_{2}$,

$$
\begin{array}{ll}
\text { then } & \frac{\partial W}{\partial(-\alpha)}<0 \text { if } \frac{1}{t}<T_{1} \text { or } \frac{1}{t}>T_{2} \\
\text { and } & \frac{\partial W}{\partial(-\alpha)}>0 \text { if } T_{1}<\frac{1}{t}<T_{2} ;
\end{array}
$$

(2) suppose $F>F_{2}$,

$$
\begin{array}{ll}
\text { then } & \frac{\partial W}{\partial(-\alpha)}>0 \quad \text { if } \quad \frac{1}{t}<T_{3} \\
\text { and } & \frac{\partial W}{\partial(-\alpha)}<0 \text { if } \frac{1}{t}>T_{3} .
\end{array}
$$

Proof: see Appendix.

We find that for relatively small values of the fixed cost $F$, welfare decreases in spillovers for rather small and rather large values of competitiveness $\frac{1}{t}$, whereas welfare increases in spillovers for intermediate values of $\frac{1}{t}$. For relatively high values of the fixed cost, welfare increases in spillovers for rather small values of $\frac{1}{t}$ while it decreases for rather large values of $\frac{1}{t}$.

Intuitively, these results can be explained as follows. Consider a situation of rather low competitive pressure $\frac{1}{t}$. In case of low fixed costs, incentives of domestic banks to invest in screening are high and rise further when spillovers fall. In contrast, for rather large values of the fixed costs, a small number of domestic banks invests in screening and rising spillovers lower the investment incentives even more. As a result, in both cases, the composition of the banking market becomes more homogeneous in the sense that either perfectly or imperfectly screening banks 
dominate the market. It follows that transport costs paid in the economy fall and, in turn, welfare increases.

However, with falling differentiation in financial products, investment incentives of domestic banks cease to vary a lot with the level of spillovers. For sufficiently large competitive pressure $\frac{1}{t}$, it is welfare optimal to limit spillover effects, independent of the size of the fixed cost. Then, the market shares of domestic banks not investing in screening fall whereas the market shares of perfectly screening banks rise entailing a decrease in the number of bad borrowers financed and, in turn, an increase in welfare.

Form Proposition 9 it can be inferred that, in general, it is welfare optimal to foster spillover effects when competitive pressure in terms of product differentiation is rather low and to limit spillovers in the presence of relatively large competitive pressure. Hence, spillovers and competitive pressure $\frac{1}{t}$ tend to work as a form of substitutes with respect to welfare. This corresponds to our previous findings of spillovers and competitive pressure $\frac{1}{t}$ behaving as substitutes with respect to the incentives of domestic banks to invest in screening.

Now, we turn to the impact of competition in terms of the number of banks operating in the market and, thus, the entry mode of foreign banks on welfare. Foreign banks should enter via a de novo investment if an increase in the number of banks operating in the market raises welfare. We find that this is the case for low fixed costs in combination with high competitive pressure $\frac{1}{t}$ as well as for high fixed costs combined with either very low or very high competitive pressure $\frac{1}{t}$, as is stated in Proposition 10.

Proposition 10 There exists a threshold $F_{3}$ for fixed costs and three thresholds $T_{4}, T_{5}$ and $T_{6}, T_{4}<T_{5}<T_{6}$, for the level of competitive pressure $\frac{1}{t}$ with the following properties:

$$
\begin{aligned}
& \text { (1) suppose } F<F_{3} \text {, } \\
& \text { then } \quad \frac{\partial W}{\partial n}<0 \quad \text { if } \frac{1}{t}<T_{6} \\
& \text { and } \quad \frac{\partial W}{\partial n}>0 \text { if } \frac{1}{t}>T_{6} \text {; }
\end{aligned}
$$


(2) suppose $F>F_{3}$,

$$
\begin{array}{ll}
\text { then } & \frac{\partial W}{\partial n}>0 \quad \text { if } \frac{1}{t}<T_{4} \text { or } \frac{1}{t}>T_{5} \\
\text { and } & \frac{\partial W}{\partial n}<0 \text { if } T_{4}<\frac{1}{t}<T_{5} .
\end{array}
$$

Proof: see Appendix.

The intuition for these results corresponds to the previous reasoning regarding spillover effects. Consider a situation of rather low competitive pressure $\frac{1}{t}$. In case of low fixed costs incentives of domestic banks to invest in screening are high and rise further when the number of banks operating in the market falls. In contrast, for large fixed costs, a small number of domestic banks invests in screening and a rising number of banks in the market lowers the investment incentives even more. Again, the composition of the banking market becomes more homogeneous, leading to a fall in the transport costs paid in the economy and, in turn, an increase in welfare.

Yet, with falling product differentiation, investment incentives of domestic banks cease to vary a lot with the number of banks operating in the market. Then, for sufficiently high competitive pressure $\frac{1}{t}$, an increase in the number of banks operating in the market is welfare improving, independent of the size of the fixed costs. Due to the fall in the market shares of all banks less borrowers with bad projects obtain financing and welfare rises.

Hence, a decreasing number of banks in the market is in general considered welfare optimal for relatively low competitive pressure $\frac{1}{t}$. In contrast, in the presence of rather high competitive pressure an increase in the number of banks is to be preferred. It follows that both channels of competition in our model tend to work as a form of complements with respect to welfare.

As a consequence, the entry of foreign banks via a de novo investment generally benefits the economy as a whole when the differentiation in financial products in the banking market is rather low. Otherwise, entry of foreign banks via the acquisition of a domestic bank is to be preferred from a welfare perspective.

We now turn to the comparison of spillovers and competition in the number of banks in their impact on welfare. In a situation of relatively small fixed costs, it 
is welfare optimal to increase spillovers but to decrease the number of banks operating in the market when competitive pressure $\frac{1}{t}$ is small. In contrast, with high competitive pressure, it is optimal to decrease spillovers but to increase the number of banks in the market. Similarly, in a situation of relatively large fixed costs, spillovers and competition in the number of banks operating in the market work in the opposite direction as well. As it was the case for spillovers and competition in terms of product differentiation, we conclude that spillovers and competition in terms of the number of banks tend to work as substitutes with respect to welfare.

Moreover, it is interesting to see that both rising spillovers and competition in the number of banks operating in the market have a clear-cut negative effect on the incentives of domestic banks to invest in screening whereas their impact on welfare is ambiguous. In contrast, although the influence of competitive pressure in terms of lower product differentiation on the incentives of domestic banks to invest in screening is ambiguous, its effect on welfare is clearly positive.

Our main results from the welfare analysis can be summarized as follows. Increasing competitive pressure $\frac{1}{t}$ clearly raises welfare. The effects of spillovers and the number of banks in the market and, thus, the entry mode of foreign banks on welfare are ambiguous. Both effects depend on the degree of product differentiation in the market. When competitive pressure $\frac{1}{t}$ is rather low, welfare tends to increase when spillovers rise and the number of banks decreases. In contrast, with relatively high competitive pressure, lower spillovers as well as a rising number of banks and, accordingly, greenfield entry tends to be preferred from a welfare perspective.

It follows that both modes of competition work as a form of complements when looking at welfare. In particular, a larger number of banks operating in the market and thus greenfield entry can, in general, only be welfare increasing when competitive pressure in terms of lower product differentiation is also sufficiently large. In that case, one sole channel of competition cannot be welfare enhancing, rather, a high level of both modes of competitive pressure is necessary for raising welfare. Second, we conclude that spillovers constitute a form of substitute relative to either mode of competition, i.e. potential positive welfare effects of spillovers 
are lower the stronger is competition.

\section{Conclusions}

We have set up a model of spatial bank competition to analyze the impact of foreign bank entry on a liberalizing banking market. In particular, we studied how the interaction of spillovers and competition affect both the incentives of domestic banks to invest in screening and welfare.

We found that spillovers and competition in the number of banks reinforce each other in their negative impact on the incentives of domestic banks to invest in screening but that the strength of both effects is mitigated with lower product differentiation. With respect to welfare, however, spillovers and either channel of competition tend to work as substitutes whereas both modes of competitive pressure rather behave as complements.

We conclude our analysis with some policy conclusions based on the results from our welfare analysis. In a first step, we could interpret different values of the fixed cost spent in order to obtain the perfect screening technology as corresponding to different stages of development in countries liberalizing their banking markets. Less developed countries would thus be characterized by larger costs for investing in screening than more developed countries. This could be due to higher costs related to the development of human capital, necessary restructuring processes or the upgrading of technical facilities. Then, when the level of differentiation in financial products is high, for very low developed countries it would be considered welfare optimal to let foreign banks enter their markets via greenfield investments whereas more developed countries should open up for foreign banks via the acquisition of domestic banks. Furthermore, very low developed countries should try to foster spillovers whereas more developed countries should seek to limit spillover effects. However, in countries with a low degree of product differentiation the preferred entry mode as well as the optimal level of spillovers would be independent of the development status of countries. As demonstrated above, a greenfield investment 
of a foreign bank is then considered the favorite entry mode and spillovers should be dampened.

We could as well apply our model to a dynamic liberalization process by assuming that shortly after the opening up of a banking market the fixed costs spent to attain better screening skills are larger than during later periods of the liberalization process. In addition, we could think of differentiation in financial products to be falling over time. On the one hand, this could be the result of an increasing transparency of the banking market or a mounting standardization of financial products which could make preferences of borrowers for a certain type of bank less pronounced. On the other hand, by the introduction of new technologies like internet banking etc., physical transportation costs of borrowers may fall alike. Hence, we could state that a country that liberalizes its banking market moves from a situation of high fixed costs and high product differentiation to an environment of low fixed costs and low product differentiation. A policy maker should then try to foster spillovers and to restrict the entry mode of foreign banks to de novo investments in the early stages of liberalization. After allowing for acquisition entry in an environment of intermediate competitive pressure, in later periods of the liberalization process the policy maker should try to limit spillovers and move to greenfield entry again. Hence, the often mentioned positive role of spillovers for financial development may be overestimated. With an increasing development of financial markets, spillovers may even harm a country and lead to a decline in welfare. 


\section{Appendix}

\section{Proof of Proposition 1:}

The condition for the marginal borrower is given by

$x_{z}=\frac{r_{z}-r}{2 t}+\frac{1}{2 n} \quad$ with $\quad z=L, H$.

It follows that the expected market share of a bank can be expressed by

$2 m\left[(1-q) x_{H}+q x_{L}\right]=m\left[\frac{(1-q) r_{H}-r+q r_{L}}{t}+\frac{1}{n}\right]$.

Hence, the profit of a domestic bank investing in screening $\pi_{D B, L}$, the profit of a domestic bank not investing in screening $\pi_{D B, H}$, and the profit of a foreign bank $\pi_{F B}$ are given by:

$\pi_{D B, L}=(r-i) \gamma m\left[\frac{(1-q) r_{H}-r+q r_{L}}{t}+\frac{1}{n}\right]-F$

$\pi_{D B, H}=(r-i) \gamma m\left[\frac{(1-q) r_{H}-r+q r_{L}}{t}+\frac{1}{n}\right]-i \alpha(1-\gamma) m\left[\frac{(1-q) r_{H}-r+q r_{L}}{t}+\frac{1}{n}\right]$

$\pi_{F B}=(r-i) \gamma m\left[\frac{(1-q) r_{H}-r+q r_{L}}{t}+\frac{1}{n}\right]$.

Banks maximize their profits with respect to the repayment they ask from borrowers which gives $r_{L}=i+\frac{t}{n}+\frac{\alpha i(1-\gamma)}{\gamma} \frac{1-q}{2}$ and $r_{H}=i+\frac{t}{n}+\frac{\alpha i(1-\gamma)}{\gamma}\left(1-\frac{q}{2}\right)$. Clearly, it holds that $r_{L}<r_{H}$.

\section{Proof of Proposition 2:}

(1) equilibrium in which all domestic banks invest in perfect screening

It must hold that $k^{*}=n-l$. Since there must not be any incentives to deviate from the equilibrium it must be satisfied that:

$\pi_{D B, L}(k=n-l) \geq \pi_{D B, H}(k=n-l-1)$ which is equivalent to

$\frac{\gamma m}{t}\left[\frac{1}{2} \frac{n-l-(n-l)}{n-1} \frac{\alpha i(1-\gamma)}{\gamma}+\frac{t}{n}\right]^{2}-F \geq \frac{\gamma m}{t}\left[-\frac{1}{2} \frac{l+(n-l-1)-1}{n-1} \frac{\alpha i(1-\gamma)}{\gamma}+\frac{t}{n}\right]^{2} \quad$ or

$F \leq \frac{n-2}{n-1}\left[\frac{m \alpha i(1-\gamma)}{n}-\frac{m(\alpha i(1-\gamma))^{2}}{4 t \gamma} \frac{n-2}{n-1}\right]:=\underline{F}$. 
(2) equilibrium in which no domestic bank invests in perfect screening

It must hold that $k^{*}=1 .^{13}$ Since there must not be any incentives to deviate from the equilibrium, it must be satisfied that:

$\pi_{D B, H}(k=1) \geq \pi_{D B, L}(k=2)$ which is equivalent to

$\frac{\gamma m}{t}\left[-\frac{1}{2} \frac{l+1-1}{n-1} \frac{\alpha i(1-\gamma)}{\gamma}+\frac{t}{n}\right]^{2} \geq \frac{\gamma m}{t}\left\{\frac{1}{2}\left[1-\frac{l+2-1}{n-1}\right] \frac{\alpha i(1-\gamma)}{\gamma}+\frac{t}{n}\right\}^{2}-F \quad$ or

$F \geq \frac{n-2}{n-1}\left[\frac{m \alpha i(1-\gamma)}{n}+\frac{m(\alpha i(1-\gamma))^{2}}{4 t \gamma} \frac{n-2 l-2}{n-1}\right]:=\bar{F}$.

(3) equilibrium in which the domestic banks coordinate about a certain number of banks investing in perfect screening

In an equilibrium in which the domestic banks coordinate about a certain number $k^{*}$ of banks investing in the perfect screening technology it must hold that given that $k^{*}$ domestic banks invest in screening all domestic banks are indifferent between investing or not investing in the screening technology. However, for $\pi_{D B, H}\left(k=\widetilde{k}^{*}\right)=\pi_{D B, L}\left(k=\widetilde{k}^{*}\right)$ there are incentives to deviate from $\widetilde{k}^{*}$ as it holds that $\frac{d \pi_{H}}{d k}=-\frac{m \alpha i(1-\gamma)}{t(n-1)}\left[\frac{t}{n}-\frac{1}{2} \frac{l+k-1}{n-1} \frac{\alpha i(1-\gamma)}{\gamma}\right]$ which is negative since the term in brackets corresponds to the market share of a domestic bank not investing in screening which must be positive. Hence, $\pi_{D B, H}\left(k=\widetilde{k}^{*}-1\right)>\pi_{D B, L}\left(k=\widetilde{k}^{*}\right)$ holds and the condition guaranteeing that there are no incentives to deviate from the equilibrium in which the domestic banks coordinate about a certain number $k^{*}$ of banks investing in perfect screening is given by:

$$
\pi_{D B, L}\left(k=k^{*}\right) \geq \pi_{D B, H}\left(k=k^{*}-1\right) \wedge \pi_{D B, H}\left(k=k^{*}\right) \geq \pi_{D B, L}\left(k=k^{*}+1\right) .
$$

This is equivalent to

$$
\begin{aligned}
& \frac{\gamma m}{t}\left\{\frac{1}{2}\left[1-\frac{l+k^{*}-1}{n-1}\right] \frac{\alpha i(1-\gamma)}{\gamma}+\frac{t}{n}\right\}^{2}-F \geq \frac{\gamma m}{t}\left[-\frac{1}{2} \frac{l+\left(k^{*}-1\right)-1}{n-1} \frac{\alpha i(1-\gamma)}{\gamma}+\frac{t}{n}\right]^{2} \wedge \\
& \frac{\gamma m}{t}\left[-\frac{1}{2} \frac{l+k^{*}-1}{n-1} \frac{\alpha i(1-\gamma)}{\gamma}+\frac{t}{n}\right]^{2} \geq \frac{\gamma m}{t}\left\{\frac{1}{2}\left[1-\frac{l+\left(k^{*}+1\right)-1}{n-1}\right] \frac{\alpha i(1-\gamma)}{\gamma}+\frac{t}{n}\right\}^{2}-F
\end{aligned}
$$

\footnotetext{
${ }^{13}$ since $q$ is defined as $q=\frac{l+k-1}{n-1}, k^{*}$ is defined to be equal to 1 in case no domestic bank invests in screening. The probability that the neighboring bank is a perfectly screening bank is then equal to $\frac{l}{n-1}$.
} 
It follows that $k^{*}$ must lie in the range

$\frac{n}{2}-l-\frac{2 t \gamma(n-1)}{\alpha i(1-\gamma)}\left[\frac{F}{m \alpha i(1-\gamma)} \frac{(n-1)}{(n-2)}-\frac{1}{n}\right] \leq k^{*} \leq \frac{n}{2}-l+1-\frac{2 t \gamma(n-1)}{\alpha i(1-\gamma)}\left[\frac{F}{m \alpha i(1-\gamma)} \frac{(n-1)}{(n-2)}-\frac{1}{n}\right]$.

We define $k^{*}=: \frac{n}{2}-l-\frac{2 t \gamma(n-1)}{\alpha i(1-\gamma)}\left[\frac{F}{m \alpha i(1-\gamma)} \frac{(n-1)}{(n-2)}-\frac{1}{n}\right]+x$ with $x \in[0 ; 1]$.

Further, it must hold that

$1<\frac{n}{2}-l-\frac{2 t \gamma(n-1)}{\alpha i(1-\gamma)}\left[\frac{F}{m \alpha i(1-\gamma)} \frac{(n-1)}{(n-2)}-\frac{1}{n}\right]$ and $\frac{n}{2}-l+1-\frac{2 t \gamma(n-1)}{\alpha i(1-\gamma)}\left[\frac{F}{m \alpha i(1-\gamma)} \frac{(n-1)}{(n-2)}-\frac{1}{n}\right]<n-l$

which simplifies to

$F<\frac{n-2}{n-1}\left[\frac{m \alpha i(1-\gamma)}{n}+\frac{m(\alpha i(1-\gamma))^{2}}{4 t \gamma} \frac{n-2 l-2}{n-1}\right]$ and $F>\frac{n-2}{n-1}\left[\frac{m \alpha i(1-\gamma)}{n}-\frac{m(\alpha i(1-\gamma))^{2}}{4 t \gamma} \frac{n-2}{n-1}\right]$.

Hence, an equilibrium in which the domestic banks coordinate about a certain number $k^{*}$ of banks investing in perfect screening exists for $\underline{F}<F<\bar{F}$.

\section{Proof of Proposition 3:}

$\frac{d k^{*}}{d(-\alpha)}=\frac{2 t \gamma(n-1)}{\alpha^{2} i(1-\gamma)}\left[\frac{1}{n}-\frac{2 F}{m \alpha i(1-\gamma)} \frac{n-1}{n-2}\right]$ and

$\frac{d k^{*}}{d(-\alpha)}<0$ if $F>\frac{1}{2} \frac{m \alpha i(1-\gamma)}{n} \frac{n-2}{n-1}$

Note that from the condition that the marginal borrower must be located in between two neighboring banks it follows that $\frac{(1-\gamma) \alpha i}{2 t \gamma} \leq \frac{1}{n}$. Note also that with $\frac{(1-\gamma) \alpha i}{2 t \gamma}=\frac{1}{n}$ the lowest possible value of $\underline{F}$ is reached and equals $\frac{1}{2} \frac{m \alpha i(1-\gamma)}{(n-1)} \frac{n-2}{n-1}:=\underline{\underline{F}}$. Since $\frac{1}{2} \frac{m \alpha i(1-\gamma)}{n} \frac{n-2}{n-1}<\underline{\underline{F}}$ it holds that $\frac{d k^{*}}{d(-\alpha)}<0$.

$\frac{d^{2} k^{*}}{d(-\alpha)^{2}}=\frac{4 t \gamma(n-1)}{(1-\gamma) i \alpha^{3}}\left[\frac{1}{n}-\frac{3 F}{m \alpha i(1-\gamma)} \frac{n-1}{n-2}\right]$ and

$\frac{d^{2} k^{*}}{d(-\alpha)^{2}}<0 \quad$ if $\quad F>\frac{1}{3} \frac{m \alpha i(1-\gamma)}{n} \frac{n-2}{n-1}$.

Since $\frac{1}{3} \frac{m \alpha i(1-\gamma)}{n} \frac{n-2}{n-1}<\underline{\underline{F}}$ it holds that $\frac{d^{2} k^{*}}{d(-\alpha)^{2}}<0$.

\section{Proof of Lemma 1:}

$\frac{d F}{d(-\alpha)}=-i(1-\gamma) m \frac{n-2}{n-1}\left[\frac{1}{n}-\frac{\alpha i(1-\gamma)}{2 t \gamma} \frac{n-2}{n-1}\right]$ and 
$\frac{d \underline{F}}{d(-\alpha)}<0 \quad$ if $\quad \frac{\alpha i(1-\gamma)}{2 t \gamma}<\frac{n-1}{n(n-2)}$.

Since $\frac{\alpha i(1-\gamma)}{2 t \gamma} \leq \frac{1}{n}$ holds, $\frac{d F}{d(-\alpha)}<0$ is satisfied.

$\frac{d \bar{F}}{d(-\alpha)}=-i(1-\gamma) m \frac{n-2}{n-1}\left[\frac{1}{n}+\frac{\alpha i(1-\gamma)}{2 t \gamma} \frac{n-2 l-2}{n-1}\right]$ and

$\frac{d \bar{F}}{d(-\alpha)}<0$ if $\quad \frac{1}{n}>-\frac{\alpha i(1-\gamma)}{2 t \gamma} \frac{n-2 l-2}{n-1}$ which is satisfied since

(i) for $n-2 l-2>0, \frac{1}{n}>-\frac{\alpha i(1-\gamma)}{2 t \gamma} \frac{n-2 l-2}{n-1}$ obviously is fulfilled and

(ii) for $n-2 l-2<0, \frac{1}{n}>-\frac{\alpha i(1-\gamma)}{2 t \gamma} \frac{n-2 l-2}{n-1}$ is equivalent to $\frac{\alpha i(1-\gamma)}{2 t \gamma}<\frac{1}{n} \frac{n-1}{2 l-n+2}$. Due to $\frac{\alpha i(1-\gamma)}{2 t \gamma} \leq \frac{1}{n}$, the condition holds if $l<n-1.5$, which is fulfilled as per definition, $k>1$.

\section{Proof of Proposition 4:}

$\frac{d k^{*}}{d n}=\frac{1}{2}-\frac{2 t \gamma}{\alpha i(1-\gamma)}\left[\frac{F(n-1)(n-3)}{m \alpha i(1-\gamma)(n-2)^{2}}-\frac{1}{n^{2}}\right]$.

Consider first $\widehat{F}=\frac{m \alpha i(1-\gamma)}{n} \frac{n-2}{n-1}-\frac{m[\alpha i(1-\gamma)]^{2}}{4 t \gamma} \frac{(n-6)(n-2)}{(n-1)^{2}}$ for which $k^{*}=n-l-2$ holds. In that case, we arrive at

$\frac{d k^{*}}{d n}=\frac{1}{2}-\frac{2 t \gamma}{\alpha i(1-\gamma)}\left\{\frac{(n-1)(n-3)}{m \alpha i(1-\gamma)(n-2)^{2}}\left[\frac{m \alpha i(1-\gamma)}{n} \frac{n-2}{n-1}-\frac{m(\alpha i(1-\gamma))^{2}}{4 t \gamma} \frac{(n-6)(n-2)}{(n-1)^{2}}\right]-\frac{1}{n^{2}}\right\}$.

If follows that $\frac{d k^{*}}{d n}<0$ if $\frac{\alpha i(1-\gamma)}{2 t \gamma}<\frac{1}{n} \frac{(n-1)\left(n^{2}-4 n+2\right)}{n\left(n^{2}-6 n+10\right)}$.

Since $\frac{\alpha i(1-\gamma)}{2 t \gamma} \leq \frac{1}{n}$ and $\frac{(n-1)\left(n^{2}-4 n+2\right)}{n\left(n^{2}-6 n+10\right)}>1$, it follows that $\frac{d k^{*}}{d n}<0$. Since $\frac{\partial^{2} k^{*}}{\partial n \partial F}=-$ $\frac{2 t \gamma(n-1)(n-3)}{m[\alpha i(1-\gamma)]^{2}(n-2)^{2}}<0, \frac{d k^{*}}{d n}<0$ also holds for $F>\widehat{F}$.

Consider second $\widetilde{F}=\frac{m \alpha i(1-\gamma)}{n} \frac{n-2}{n-1}-\frac{m[\alpha i(1-\gamma)]^{2}}{4 t \gamma} \frac{(n-4)(n-2)}{(n-1)^{2}}$ for which $k^{*}=n-l-1$ holds. In that case, we arrive at

$\frac{d k^{*}}{d n}=\frac{1}{2}-\frac{2 t \gamma}{\alpha i(1-\gamma)}\left\{\frac{(n-1)(n-3)}{m \alpha i(1-\gamma)(n-2)^{2}}\left[\frac{m \alpha i(1-\gamma)}{n} \frac{n-2}{n-1}-\frac{m(\alpha i(1-\gamma))^{2}}{4 t \gamma} \frac{(n-4)(n-2)}{(n-1)^{2}}\right]-\frac{1}{n^{2}}\right\}$.

If follows that $\frac{d k^{*}}{d n}<0$ if $\frac{\alpha i(1-\gamma)}{2 t \gamma}<\frac{1}{n} \frac{(n-1)\left(n^{2}-4 n+2\right)}{n\left(n^{2}-5 n+7\right)}$.

Since $\frac{\alpha i(1-\gamma)}{2 t \gamma} \leq \frac{1}{n}$ but $\frac{(n-1)\left(n^{2}-4 n+2\right)}{n\left(n^{2}-5 n+7\right)}<1$ is possible, $\frac{d k^{*}}{d n}>0$ is feasible for $F=\widetilde{F}$. However, $k^{*}(n+1, \widetilde{F})<k^{*}(n, \widetilde{F})$ if $\frac{\alpha i(1-\gamma)}{2 t \gamma}<\frac{1}{n+1} \frac{2 n(n-1)(n-3)}{2 n^{3}-10 n^{2}+16 n-5}$. Since 
$\frac{\alpha i(1-\gamma)}{2 t \gamma} \leq \frac{1}{n+1}$ must hold and $\frac{2 n(n-1)(n-3)}{16 n-10 n^{2}+2 n^{3}-5}>1, k^{*}(n+1, \widetilde{F})<k^{*}(n, \widetilde{F})$ holds. Thus, with a rising number of banks, the number of domestic banks investing in perfect screening falls.

$\frac{d^{2} k^{*}}{d n^{2}}=-\frac{2 t \gamma}{\alpha i(1-\gamma)}\left[\frac{2}{n^{3}}+\frac{2 F}{m \alpha i(1-\gamma)(n-2)^{3}}\right]$ is clearly negative.

\section{Proof of Lemma 2:}

$\frac{d \underline{F}}{d n}=-\frac{m \alpha i(1-\gamma)}{(n-1)^{2}}\left[\frac{n^{2}-4 n+2}{n^{2}}+\frac{\alpha i(1-\gamma)}{2 t \gamma} \frac{n-2}{n-1}\right]$ and

$\frac{d F}{d n}<0 \quad$ if $\quad \frac{\alpha i(1-\gamma)}{2 t \gamma}>-\frac{1}{n} \frac{n^{2}-4 n+2}{n} \frac{n-1}{n-2}$ which is satisfied.

$\frac{d \bar{F}}{d n}=-\frac{m a i(1-\gamma)}{(n-1)^{2}}\left[\frac{n^{2}-4 n+2}{n^{2}}-\frac{\alpha i(1-\gamma)}{2 t \gamma} \frac{n+l(n-3)-2}{n-1}\right]$ and

$\frac{d \bar{F}}{d n}<0$ if $\frac{l}{n}<\frac{(n-2)(n-4)-\frac{2}{n}}{(n-3) n}$

Note that $\lim _{n \longrightarrow \infty} \frac{(n-2)(n-4)-\frac{2}{n}}{(n-3) n}=1$. Hence, $\frac{d \bar{F}}{d n}<0$ holds for not too large shares of foreign banks in the market.

\section{Proof of Lemma 3:}

Share of all perfectly screening banks in the market in case of acquisition entry:

We start from an equilibrium in which the share of all perfectly screening banks is given by $\frac{k^{*}+l}{n}$. By opening the market for a marginal foreign bank to enter via acquisition we arrive at $\frac{k^{*}+d k_{A}^{*}+l+d l}{n}$. Since $d k_{A}^{*}=-d l$ it holds that $\frac{k^{*}+d k_{A}^{*}+l+d l}{n}=$ $\frac{k^{*}+l}{n}$.

Share of all perfectly screening banks in the market in case of greenfield entry:

We start from an equilibrium in which the share of all perfectly screening banks is given by $\frac{k^{*}+l}{n}$. By opening the market for a marginal foreign bank to enter via a de novo investment we arrive at $\frac{k^{*}+d k_{G}^{*}+l+d l}{n+d n}$. Since $d k_{G}^{*}=-d l+\left\{\frac{1}{2}-\right.$ 
$\left.\frac{2 t \gamma}{\alpha i(1-\gamma)}\left[\frac{F(n-1)(n-3)}{m \alpha i(1-\gamma)(n-2)^{2}}-\frac{1}{n^{2}}\right]\right\} d n$, the share of perfectly screening banks in the market becomes $\frac{k^{*}+l+\left\{\frac{1}{2}-\frac{2 t \gamma}{\alpha i(1-\gamma)}\left[\frac{F(n-1)(n-3)}{m \alpha i(1-\gamma)(n-2)^{2}}-\frac{1}{n^{2}}\right]\right\} d n}{n+d n}$. Provided that a marginal foreign bank enters, we can set $d n=1$. Note further, that $\frac{1}{2}-\frac{2 t \gamma}{\alpha i(1-\gamma)}\left[\frac{F(n-1)(n-3)}{m \alpha i(1-\gamma)(n-2)^{2}}-\frac{1}{n^{2}}\right]<1$ if $F>\frac{(n-2)^{2}}{(n-1)(n-3)}\left[\frac{m \alpha i(1-\gamma)}{n^{2}}-\frac{m(\alpha i(1-\gamma))^{2}}{4 t \gamma}\right]$. Since $\frac{(n-2)^{2}}{(n-1)(n-3)}\left[\frac{m \alpha i(1-\gamma)}{n^{2}}-\frac{m(\alpha i(1-\gamma))^{2}}{4 t \gamma}\right]<\underline{\underline{F}}$, it holds that $\frac{k^{*}+l+\left\{\frac{1}{2}-\frac{2 t \gamma}{\alpha i(1-\gamma)}\left[\frac{F(n-1)(n-3)}{m \alpha i(1-\gamma)(n-2)^{2}}-\frac{1}{n^{2}}\right]\right\} d n}{n+d n}<\frac{k^{*}+l}{n}$.

\section{Proof of Proposition 5:}

$\frac{\partial^{2} k^{*}}{\partial(-\alpha) \partial n}=\frac{2 t \gamma}{n^{2} \alpha^{2} i(1-\gamma)}-\frac{4 t \gamma F}{m \alpha^{3} i^{2}(1-\gamma)^{2}} \frac{(n-1)(n-3)}{(n-2)^{2}}$ and

$\frac{\partial^{2} k^{*}}{\partial(-\alpha) \partial n}<0$ if $F>\frac{1}{2} \frac{m \alpha i(1-\gamma)}{(n-1)} \frac{(n-2)^{2}}{n^{2}(n-3)}$.

Since $\frac{1}{2} \frac{m \alpha i(1-\gamma)}{(n-1)} \frac{(n-2)^{2}}{n^{2}(n-3)}<\underline{\underline{F}}$ it holds that $\frac{\partial^{2} k^{*}}{\partial(-\alpha) \partial n}<0$.

\section{Proof of Proposition 6:}

$\frac{d k^{*}}{d\left(\frac{1}{t}\right)}=\frac{2 t^{2} \gamma(n-1)}{\alpha i(1-\gamma)}\left[\frac{F}{m \alpha i(1-\gamma)} \frac{n-1}{n-2}-\frac{1}{n}\right]$ and

$\frac{d k^{*}}{d\left(\frac{1}{t}\right)}>0$ if $F>\frac{m \alpha i(1-\gamma)}{n} \frac{n-2}{n-1}$ and $\frac{d k^{*}}{d\left(\frac{1}{t}\right)}<0$ if $F<\frac{m \alpha i(1-\gamma)}{n} \frac{n-2}{n-1}$.

We define $F_{1}:=\frac{m \alpha i(1-\gamma)}{n} \frac{n-2}{n-1}$.

$\frac{d^{2} k^{*}}{d\left(\frac{1}{t}\right)^{2}}=\frac{4 \gamma t^{3}(n-1)}{\alpha i(1-\gamma)}\left[\frac{1}{n}-\frac{F}{m \alpha i(1-\gamma)} \frac{n-1}{n-2}\right]$ and

$\frac{d^{2} k^{*}}{d\left(\frac{1}{t}\right)^{2}}>0$ if $F<F_{1}$ and $\frac{d^{2} k^{*}}{d\left(\frac{1}{t}\right)^{2}}<0$ if $F>F_{1}$.

Note that $F>F_{1}$ is only possible if $F_{1}<\bar{F}$ which holds for $l<\frac{n-2}{2}$.

\section{Proof of Proposition 7:}

$\frac{\partial^{2} k^{*}}{\partial(-\alpha) \partial\left(\frac{1}{t}\right)}=\frac{2 \gamma t^{2}(n-1)}{\alpha^{2} i(1-\gamma)}\left[\frac{2 F(n-1)}{m \alpha i(1-\gamma)(n-2)}-\frac{1}{n}\right]$ and

$\frac{\partial^{2} k^{*}}{\partial(-\alpha) \partial\left(\frac{1}{t}\right)}>0$ if $F>\frac{1}{2} \frac{m \alpha i(1-\gamma)}{n} \frac{n-2}{n-1}$. 
Since $\frac{1}{2} \frac{m \alpha i(1-\gamma)}{n} \frac{n-2}{n-1}<\underline{\underline{F}}$ it holds that $\frac{\partial^{2} k^{*}}{\partial(-\alpha) \partial\left(\frac{1}{t}\right)}>0$.

$\frac{\partial^{2} k^{*}}{\partial n \partial\left(\frac{1}{t}\right)}=\frac{2 \gamma t^{2}}{\alpha i(1-\gamma)}\left[\frac{F(n-1)(n-3)}{m \alpha i(1-\gamma)(n-2)^{2}}-\frac{1}{n^{2}}\right]$ and

$\frac{\partial^{2} k^{*}}{\partial n \partial\left(\frac{1}{t}\right)}>0$ if $F>\frac{\operatorname{mai}(1-\gamma)}{n^{2}} \frac{(n-2)^{2}}{(n-1)(n-3)}$.

Since $\frac{m a i(1-\gamma)}{n^{2}} \frac{(n-2)^{2}}{(n-1)(n-3)}<\underline{\underline{F}}$ it holds that $\frac{\partial^{2} k^{*}}{\partial n \partial\left(\frac{1}{t}\right)}>0$.

\section{Proof of Proposition 8:}

\section{Set-up of the Social Welfare Function:}

Welfare consists of the sum of borrower rents and bank rents. Borrower rents are captured by the willingness to pay of borrowers minus the repayments of borrowers to banks and their transport costs. Bank rents include the revenues of banks minus their costs. ${ }^{14}$

Transport costs are given by

$2 m\left(k^{*}+l\right)\left[\frac{n-l-k^{*}}{n-1} \int_{0}^{\frac{1}{2 n}+\frac{\alpha i(1-\gamma)}{4 t \gamma}} t x d x+\frac{l+k^{*}-1}{n-1} \int_{0}^{\frac{1}{2 n}} t x d x\right]+$

$2 m\left(n-l-k^{*}\right)\left[\frac{n-l-k^{*}}{n-1} \int_{0}^{\frac{1}{2 n}} t x d x+\frac{l+k^{*}-1}{n-1} \int_{0}^{\frac{1}{2 n}-\frac{\alpha i(1-\gamma)}{4 t \gamma}} t x d x\right]=$

$\operatorname{tm}\left\{\frac{n-k^{*}-l}{n-1} \frac{\alpha i(1-\gamma)}{4 t \gamma}\left[\frac{\alpha i(1-\gamma)}{4 t \gamma}\left(2 k^{*}+2 l-1\right)+\frac{1}{n}\right]+\frac{1}{4 n}\right\}$.

Since the repayments of borrowers to banks equal the revenues of banks, welfare can be expressed as

\footnotetext{
${ }^{14}$ In order to analytically solve for the welfare implications, we focus on the following parameter ranges throughout section 5 . We assume that the share of borrowers with good projects is larger than one half and not arbitrarily close to its boundary values, and that spillovers are not too large i.e. $1-\alpha<0.75$.
} 


$$
\begin{aligned}
W= & v m \gamma+0 \cdot m(1-\gamma)-\operatorname{tm}\left\{\frac{n-k^{*}-l}{n-1} \frac{\alpha i(1-\gamma)}{4 t \gamma}\left[\frac{\alpha i(1-\gamma)}{4 t \gamma}\left(2 k^{*}+2 l-1\right)+\frac{1}{n}\right]+\frac{1}{4 n}\right\}- \\
& k^{*} m i \gamma\left[\frac{n-l-k^{*}}{n-1} \frac{\alpha i(1-\gamma)}{2 t \gamma}+\frac{1}{n}\right]-k^{*} F-l m i \gamma\left[\frac{n-l-k^{*}}{n-1} \frac{\alpha i(1-\gamma)}{2 t \gamma}+\frac{1}{n}\right]- \\
& \left(n-l-k^{*}\right) i m\left[-\frac{l+k^{*}-1}{n-1} \frac{\alpha i(1-\gamma)}{2 t \gamma}+\frac{1}{n}\right][\gamma+(1-\gamma) \alpha]
\end{aligned}
$$

\section{Effect of competitive pressure $\frac{1}{t}$ on welfare:}

$$
\begin{aligned}
\frac{\partial W}{\partial\left(\frac{1}{t}\right)}= & \frac{1}{32 m n \gamma^{2}[\alpha i(1-\gamma)]^{2}(n-1)(n-2)^{2}}\left\{[ m \alpha i ( 1 - \gamma ) ( n - 2 ) ] ^ { 2 } \left[\alpha(1-\gamma) i^{2} n(n-2 x)\right.\right. \\
& \left.(\alpha(1-\gamma)(4 \gamma-1)(n-1+2 x)-4 \gamma(\alpha(1-\gamma)+2 \gamma))-8 t^{2} \gamma^{2}(n-1)\right]-F \\
& {\left.[4 t \gamma(n-1)]^{2}[F n(n-1)(n-4 \gamma-1)-m \alpha i(1-\gamma)(n-2)(2 n-4 \gamma-1)]\right\} . }
\end{aligned}
$$

$\frac{\partial W}{\partial\left(\frac{1}{t}\right)}>0$ holds if

$\left(\frac{1}{t}\right)^{2}>\frac{8(n-1)[m \gamma \alpha i(1-\gamma)(n-2)]^{2}+F[4 \gamma(n-1)]^{2}[F n(n-1)(n-4 \gamma-1)-m \alpha i(1-\gamma)(n-2)(2 n-4 \gamma-1)]}{i n m^{2}[\alpha i(1-\gamma)]^{3}(n-2)^{2}(n-2 x)[\alpha(1-\gamma)(4 \gamma-1)(n-1+2 x)-4 \gamma(\alpha(1-\gamma)+2 \gamma)]} \cdot{ }^{15}$

$\frac{\partial W}{\partial\left(\frac{1}{t}\right)}>0$ is satisfied for

$\frac{8(n-1)[m \gamma \alpha i(1-\gamma)(n-2)]^{2}+F[4 \gamma(n-1)]^{2}[F n(n-1)(n-4 \gamma-1)-m \alpha i(1-\gamma)(n-2)(2 n-4 \gamma-1)]}{i n m^{2}[\alpha i(1-\gamma)]^{3}(n-2)^{2}(n-2 x)[\alpha(1-\gamma)(4 \gamma-1)(n-1+2 x)-4 \gamma(\alpha(1-\gamma)+2 \gamma)]}<0$.

This inequality holds for

$F_{2}\left[1-\sqrt{1-\frac{2 n(n-4 \gamma-1)}{(2 n-4 \gamma-1)^{2}}}\right]<F<F_{2}\left[1+\sqrt{1-\frac{2 n(n-4 \gamma-1)}{(2 n-4 \gamma-1)^{2}}}\right]$

with $F_{2}:=\frac{1}{2} \frac{\operatorname{moi}(1-\gamma)}{n} \frac{n-2}{n-1} \frac{2 n-4 \gamma-1}{n-4 \gamma-1}$.

(i) Proof of $F>F_{2}\left[1-\sqrt{1-\frac{2 n(n-4 \gamma-1)}{(2 n-4 \gamma-1)^{2}}}\right]$ :

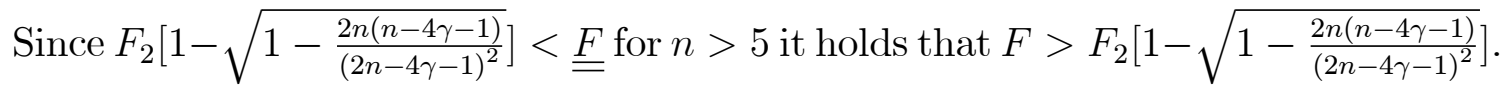

(ii) Proof of $F<F_{2}\left[1+\sqrt{1-\frac{2 n(n-4 \gamma-1)}{(2 n-4 \gamma-1)^{2}}}\right]$ :

\footnotetext{
${ }^{15}$ We assume that $n$ is not too small and that $\gamma$ is not too close to its boundary values such that $\alpha(1-\gamma)(4 \gamma-1)(n-1+2 x)-4 \gamma[\alpha(1-\gamma)+2 \gamma]>0$.
} 
Note that with $\frac{(1-\gamma) \alpha i}{2 t \gamma}=\frac{1}{n}$ the highest possible value of $\bar{F}$ is reached and equals $\frac{\operatorname{mai}(1-\gamma)}{n} \frac{n-2}{n-1}\left[\frac{3}{2}-\frac{2 l+1}{2(n-1)}\right]$. Further, $F_{2}\left[1+\sqrt{1-\frac{2 n(n-4 \gamma-1)}{(2 n-4 \gamma-1)^{2}}}\right]>\frac{3}{2} \frac{\operatorname{mai}(1-\gamma)}{n} \frac{n-2}{n-1}$ holds for $n>5$ such that $F<F_{2}\left[1+\sqrt{1-\frac{2 n(n-4 \gamma-1)}{(2 n-4 \gamma-1)^{2}}}\right]$ holds.

\section{Proof of Proposition 9:}

$$
\begin{aligned}
\frac{\partial W}{\partial(-\alpha)}= & -\frac{1}{\alpha m n(n-1)[4 \alpha i \gamma(1-\gamma)(n-2)]^{2}}\left\{-m^{2}(n-2)^{2}[\alpha i(1-\gamma)]^{3}\left[\frac{i n}{t}(n-2 x)\right.\right. \\
& {[4 \gamma(\gamma+\alpha(1-\gamma))-\alpha(1-\gamma)(4 \gamma-1)(n-1+2 x)]+} \\
& \left.2 \gamma\left[4 \gamma(n-1)^{2}+(2 x-1)((n-1)(4 \gamma-1)-n)\right]\right]-8 F t \gamma^{2}(n-1)^{2} \\
& {\left.\left[2 F n(n-1)(n-4 \gamma-1)-m \alpha i(1-\gamma)(n-2)\left(2 n-4 \gamma-1+\frac{2 i n \gamma}{t}\right)\right]\right\} . }
\end{aligned}
$$

$\frac{\partial W}{\partial(-\alpha)}>0$ holds if

$T_{1}<\frac{1}{t}<T_{2}$

with $T_{1}:=A(1-\sqrt{1-B})$ and $T_{2}:=A(1+\sqrt{1-B})$ and

$A:=\frac{8 F i n \gamma^{3}(n-1)^{2}-m \gamma[\alpha i(1-\gamma)]^{2}(n-2) C_{1}}{m[\alpha i(1-\gamma)]^{2} n(n-2)(n-2 x) C_{2}}$

$B:=\frac{8 F \alpha i(1-\gamma) \gamma^{2} n(n-1)^{2}(n-2 x)[2 F n(n-1)(n-4 \gamma-1)-m \alpha i(1-\gamma)(n-2)(2 n-4 \gamma-1)] C_{2}}{\left[8 F i \gamma^{3} n(n-1)^{2}-m \gamma(\alpha i(1-\gamma))^{2}(n-2) C_{1}\right]^{2}}$

$C_{1}:=4 \gamma(n-1)^{2}+(2 x-1)[(n-1)(4 \gamma-1)-n]>0$

$C_{2}:=i[4 \gamma[\gamma+\alpha(1-\gamma)]-\alpha(1-\gamma)(4 \gamma-1)(n-1+2 x)]<0$

Note that $A>0$ holds if $F<\frac{m \alpha i(1-\gamma)}{n} \frac{n-2}{n-1} \frac{\alpha(1-\gamma) C_{1}}{8 \gamma^{2}(n-1)}$.

Remember that $\bar{F} \leq \frac{3}{2} \frac{m \alpha i(1-\gamma)}{n} \frac{n-2}{n-1}$. Further, $\frac{\alpha(1-\gamma) C_{1}}{8 \gamma^{2}(n-1)}>\frac{3}{2}$ is satisfied for $n>13$. Hence, $F<\frac{\operatorname{mai}(1-\gamma)}{n} \frac{n-2}{n-1} \frac{\alpha(1-\gamma) C_{1}}{8 \gamma^{2}(n-1)}$ is fulfilled and $A>0$ holds.

It follows from $A>0$ that

(i) $T_{2}>0$ and

(ii) $T_{1}>0$ if $0<B<1$ and $T_{1}<0$ if $B<0$.

Note that $B>0$ is equivalent to $F<F_{2}$. 
Further, it is easily verified that $\left.T_{2}\right|_{F>F_{2}}>\left.T_{2}\right|_{F<F_{2}}$. We define $T_{3}:=\left.T_{2}\right|_{F>F_{2}}$.

It follows that

(i) for $F<F_{2}, \frac{\partial W}{\partial(-\alpha)}<0$ if $\frac{1}{t}<T_{1}$ or $\frac{1}{t}>T_{2}$ and $\frac{\partial W}{\partial(-\alpha)}>0$ if $T_{1}<\frac{1}{t}<T_{2}$;

(ii) for $F>F_{2}, \frac{\partial W}{\partial(-\alpha)}>0$ if $\frac{1}{t}<T_{3}$ and $\frac{\partial W}{\partial(-\alpha)}<0$ if $\frac{1}{t}>T_{3}$.

\section{Proof of Proposition 10:}

$$
\begin{aligned}
\frac{\partial W}{\partial n}= & -\frac{1}{32(\alpha i(1-\gamma))^{2} m n^{2} t \gamma^{2}(n-1)^{2}(n-2)^{3}}\left\{( m \alpha i ( 1 - \gamma ) ) ^ { 2 } ( n - 2 ) ^ { 3 } \left[2 \alpha i ( 1 - \gamma ) x \left[\alpha i(1-\gamma) n^{2}\right.\right.\right. \\
& {\left.\left[(4 \gamma-1)(1-2 x)+4 \gamma\left(1+\frac{2 \gamma}{\alpha(1-\gamma)}\right)\right]+4 t \gamma\left(n^{2}-(n-1)^{2}(4 \gamma-1)\right)\right]+4 t \gamma\left[(n-1)^{2}\right.} \\
& \left.\left(8 i \gamma^{2}(1-\alpha)+\alpha i(8 \gamma-1)+2 t \gamma\right)+\alpha i\left(n^{2}(2 \gamma-1)-\gamma(2 n-1)\right)\right]-(n \alpha i(1-\gamma))^{2} \\
& {\left.\left[\left((4 \gamma-1)(n-1)^{2}+4 \gamma\right)+\frac{8 \gamma^{2}}{\alpha(1-\gamma)}\right]\right]-4 t \gamma(n-1)^{2} F\left[4 t \gamma F n^{2}(n-1)[(n-1)(n-4)\right.} \\
& +8 \gamma]-m \alpha i(1-\gamma)(n-2)\left[i n^{2}[\alpha(1-\gamma)(4 \gamma(n-1)(n-2)-4 \gamma(n-4 x)+1\right. \\
& \left.\left.\left.\left.-4 x)-8 \gamma^{2}\right]+4 t \gamma\left[n^{2}(4 \gamma-1)-2(4 \gamma+1)(n-1)\right]\right]\right]\right\}
\end{aligned}
$$

$\frac{\partial W}{\partial n}<0$ holds if

$T_{4}<\frac{1}{t}<T_{5}$

with $T_{4}:=D(1-\sqrt{1-E})$ and $T_{5}:=D(1+\sqrt{1-E})$ and

$D:=-\frac{2 i \gamma\left[m \alpha i(1-\gamma)(n-2)^{2} G_{1}+n^{2}(n-1)^{2} F G_{4}\right]}{m[i \alpha(1-\gamma)]^{3} n^{2}(n-2)^{2} G_{2}}$

$E:=\frac{2(n-2)[\alpha(1-\gamma) n(n-1)]^{2}\left[(m \alpha i(1-\gamma))^{2}(n-2)^{3}-2 F G_{3}\right] G_{2}}{\left[m \alpha i(1-\gamma)(n-2)^{2} G_{1}+n^{2}(n-1)^{2} F G_{4}\right]^{2}}$

$G_{1}:=4 \gamma(n-1)^{2}[\alpha(1-\gamma)+2 \gamma]-\alpha(1-\gamma)(1-2 x)\left[2 n(n-1)+1-4 \gamma(n-1)^{2}\right]$

$G_{2}:=\left[8 \gamma-1+\frac{8 \gamma^{2}}{\alpha(1-\gamma)}\right](2 x-1)-(4 \gamma-1)\left[n(n-2)+4 x^{2}\right]$

$G_{3}:=F n^{2}(n-1)[(n-1)(n-4)+8 \gamma]-$

$\operatorname{m\alpha i}(1-\gamma)(n-2)\left[n^{2}(4 \gamma-1)-2(4 \gamma+1)(n-1)\right]$

$G_{4}:=\alpha(1-\gamma)\left[4 \gamma\left(n^{2}-4 n+2\right)+1+4 x(4 \gamma-1)\right]-8 \gamma^{2}$

It is useful to show for further proofs that (i) $G_{1}>0$, (ii) $G_{2}<0$ and (iii) $G_{4}>0$. 
(i) Proof of $G_{1}>0$ :

Note that for $x=1, G_{1}$ simplifies to $8 \gamma^{2}(n-1)^{2}+\alpha(1-\gamma)[2 n(n-1)+1]$ which clearly is positive. Note that $\frac{d G_{1}}{d x}=2 \alpha(1-\gamma)\left[2 n(n-1)+1-4 \gamma(n-1)^{2}\right]$. Since $2 n(n-1)+1-4 \gamma(n-1)^{2}<0^{16}$ it follows that $G_{1}>0$ holds also for $x<1$.

(ii) Proof of $G_{2}<0$ :

For $x=1, G_{2}$ equals $8 \gamma-1+\frac{8 \gamma^{2}}{\alpha(1-\gamma)}-(4 \gamma-1)[n(n-2)+4]<0 .{ }^{17}$ Further, $\frac{d G_{2}}{d x}>0$ for $x<\frac{8 \gamma-1}{4(4 \gamma-1)}+\frac{2 \gamma^{2}}{\alpha(1-\gamma)(4 \gamma-1)}$. Since $\frac{8 \gamma-1}{4(4 \gamma-1)}+\frac{2 \gamma^{2}}{\alpha(1-\gamma)(4 \gamma-1)}>1$ it holds that $G_{2}<0$.

(iii) Proof of $G_{4}>0$ :

$G_{4}>0$ holds if $\alpha>\frac{8 \gamma^{2}}{(1-\gamma)\left[4 \gamma\left(n^{2}-4 n+2\right)+1+4 x(4 \gamma-1)\right]}$. Further, for $x=0$ the condition simplifies to $\alpha>\frac{8 \gamma^{2}}{(1-\gamma)\left[4 \gamma\left(n^{2}-4 n+2\right)+1\right]}$ which holds. ${ }^{17}$ Hence,

$\alpha>\frac{8 \gamma^{2}}{(1-\gamma)\left[4 \gamma\left(n^{2}-4 n+2\right)+1+4 x(4 \gamma-1)\right]}$ is also satisfied for $x>0$ and thus, $G_{4}>0$ holds.

We now show that $D>0 . D>0$ holds if $G_{2}<0$ and $m \alpha i(1-\gamma)(n-2)^{2} G_{1}+$ $n^{2}(n-1)^{2} F G_{4}>0$, with the first condition already proved. The second condition is equivalent to $F>-\frac{m \alpha i(1-\gamma)}{n^{2}} \frac{(n-2)^{2}}{(n-1)^{2}} \frac{G_{1}}{G_{4}}$. Since $G_{1}>0$ and $G_{4}>0$, this condition clearly is satisfied and $D>0$ holds.

It follows from $D>0$ that

(i) $T_{5}>0$ and

(ii) $T_{4}>0$ if $0<E<1$ and $T_{4}<0$ if $E<0$.

Note that $E<0$ is equivalent to

$F_{4}<F<F_{3}$

with $F_{4}:=H(1-\sqrt{1+J})$ and $F_{3}:=H(1+\sqrt{1+J})$ and

$H:=\frac{m \alpha i(1-\gamma)(n-2)\left[n^{2}(4 \gamma-1)-2(4 \gamma+1)(n-1)\right]}{2 n^{2}(n-1)[(n-1)(n-4)+8 \gamma]}$

\footnotetext{
${ }^{16}$ for $\gamma$ not too close to 0.5 and $n$ not too small

${ }^{17}$ for $\gamma$ not too close to 1 and $n$ not too small
} 
$J:=\frac{2(n-1)(n-2) n^{2}[(n-1)(n-4)+8 \gamma]}{\left[n^{2}(4 \gamma-1)-2(4 \gamma+1)(n-1)\right]^{2}}$.

Note that since $n^{2}(4 \gamma-1)-2(4 \gamma+1)(n-1)>0$ it holds that $H>0$ and $J>0$ clearly holds.

It follows from $J>0$ that $F_{4}<0$. Hence, it holds that $E<0$ and thus $T_{4}<0$ for $F<F_{3}$ and $E>0$ and thus $T_{4}>0$ for $F>F_{3}$.

Further, it is easily verified that $\left.T_{5}\right|_{F<F_{3}}>\left.T_{5}\right|_{F>F_{3}}$. We define $T_{6}:=\left.T_{5}\right|_{F<F_{3}}$.

It follows that

(i) for $F<F_{3}, \frac{\partial W}{\partial n}<0$ if $\frac{1}{t}<T_{6}$ and $\frac{\partial W}{\partial n}>0$ if $\frac{1}{t}>T_{6}$;

(ii) for $F>F_{3}, \frac{\partial W}{\partial n}>0$ if $\frac{1}{t}<T_{4}$ or $\frac{1}{t}>T_{5}$ and $\frac{\partial W}{\partial n}<0$ if $T_{4}<\frac{1}{t}<T_{5}$. 


\section{References}

Aghion, P. and M. Schankerman. (2004). "On the Welfare Effects and Political Economy of Competition-enhancing Policies." The Economic Journal 114, 800824.

Beck, T., Levine, R. and N. Loayza. (2000). "Finance and the Sources of Growth." Journal of Financial Economics, 58, 261-300.

Blomström, M. and A. Kokko. (1998). "Multinational Corporations and Spillovers." Journal of Economic Surveys, 12(3), 247-277.

Boot, A. W. A. and M. Marinč. (2006). "Competition and Entry in Banking: Implications for Stability and Capital Regulation." CEPR Discussion Paper 5518.

Broecker, T. (1990). "Credit-worthiness Tests and Interbank Competition." Econometrica, 58(2), 429-452.

Buch, C. M. (2003). "Information or Regulation: What Drives the International Activities of Commercial Banks?" Journal of Money, Credit, and Banking, 35(6), 851-869.

Ceccagnoli, M. (2005). "Firm Heterogeneity, Imitation, and the Incentives for Cost Reducing R\&D Effort." The Journal of Industrial Economics, 53(1), 83-100.

Claessens, S., Demirgüç-Kunt, A. and H. Huizinga. (2001). "How Does Foreign Entry Affect the Domestic Banking Market?" Journal of Banking and Finance, 25(5), 891-911.

Claeys, S. and C. Hainz. (2006). "Acquisition versus Greenfield: the Impact of the Mode of Foreign Bank Entry on Information and Bank Lending Rates. Theory and Evidence." Working paper.

Clarke, G. et al. (2003). "Foreign Bank Entry: Experience, Implications for Developing Countries and Agenda for Further Research." Oxford University Press. World Bank Research Observer, 18(1), 25-59. 
Coe, D. T. and E. Helpman. (1995). "International R\&D Spillovers." European Economic Review, 39, 859 - 887.

Coe, D. T., Helpman, E. and A. W. Hoffmaister. (1997). "North-south R\&D Spillovers." The Economic Journal, 107(440), 134-149.

Cohen, W. M. and D. A. Levinthal. (1989). "Innovation and Learning: the Two Faces of R\&D." The Economic Journal, 99(397), S. 569-596.

Dell'Ariccia, G., Friedman, E. and R. Marquez. (1999). "Adverse Selection as a Barrier to Entry in the Banking Industry." The RAND Journal of Economics, $30(3), 515-534$.

Dell'Ariccia, G. and R. Marquez. (2004). "Information and Bank Credit Allocation." Journal of Financial Economics, 72, 185-214.

Fries, S. and A. Taci. (2005). "Cost Efficiency of Banks in Transition: Evidence from 289 Banks in 15 Post-communist Countries." Journal of Banking and Finance, 29(1), 55-81.

Görg, H. and E. Strobl. (2001). "Multinational Companies and Productivity Spillovers: a Meta-analysis." The Economic Journal, 111, F723-F739.

Goldberg, L. (2004). "Financial-sector FDI and Host Countries: New and Old Lessons." NBER Working Paper 10441.

Hauswald, R. and R. Marquez. (2003). "Information Technology and Financial Services Competition." The Review of Financial Studies, 16(3), 921-948.

Hauswald, R. and R. Marquez. (2005). "Competition and Strategic Information Acquisition in Credit Markets." forthcoming. The Review of Financial Studies.

Kaas, L. (2004). "Financial Market Integration and Loan Competition - When is Entry Deregulation Socially Beneficial?" ECB Working Paper 403.

Levin, R. C. and P. C. Reiss. (1988). "Cost-reducing and Demand-creating R\&D with Spillovers." The RAND Journal of Economics, 19(4), 538-556. 
Martinez Peria, M. S. and A. Mody. (2004). "How Foreign Participation and Market Concentration Impact Bank Spreads: Evidence from Latin America." Journal of Money, Credit and Banking, 36(3), 511-537.

Panetta, F., Schivardi, F. and M. Shum. (2005). "Do Mergers Improve Information? Evidence from the loan market." CEPR Discussion Paper 4961.

Raith, M. (2003). "Competition, Risk, and Managerial Incentives." The American Economic Review, 93(4), 1425-1436.

Schnitzer, M. (1999). "Enterprise Restructuring and Bank Competition in Transition Economies." The Economics of Transition, 7(1), 133-155.

Sharpe, S. A. (1990). "Asymmetric Information, Bank Lending and Implicit Contracts: a Stylized Model of Customer Relationships." The Journal of Finance, 45(4), 1069-1087.

Spence, M. (1984). "Cost Reduction, Competition, and Industry Performance." Econometrica, 52(1), 101-122.

Van Tassel, E. and S. Vishwasrao. (2005). "Asymmetric Information and the Mode of Entry in Foreign Credit Markets." Working paper.

Vives, X. (2004). "Innovation and Competitive Pressure." CEPR Working Paper 4369. 